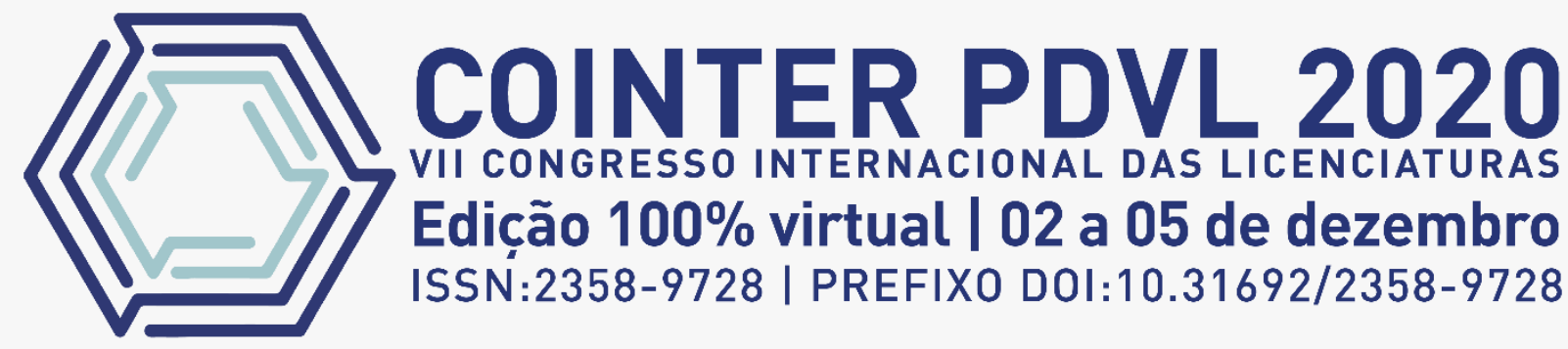

\title{
IMPLICAÇÕES DA GESTÃo DEMOCRÁTICA NA CONSTRUÇÃO DO PROJETO POLÍTICO PEDAGÓGICO E OS REFLEXOS DA PANDEMIA
}

\author{
IMPLICACIONES DE LA GESTIÓN DEMOCRÁTICA EN LA CONSTRUCCIÓN \\ DEL PROYECTO LA POLÍTICA PEDAGÓGICA Y LOS REFLEXIONES DE LA \\ PANDEMIA
}

\section{IMPLICATIONS OF DEMOCRATIC MANAGEMENT IN THE PROJECT CONSTRUCTION PEDAGOGICAL POLICY AND THE REFLECTIONS OF THE PANDEMIC}

\author{
Apresentação: Comunicação Oral
}

José Roniero Diodato ${ }^{1}$; Jaqueline Costa da Silva Lima $^{2}$; Adriana Patrícia da Silva ${ }^{3 ;}$ Lúcio Costa de Andrade ${ }^{4}$; Suzana Pereira Temudo ${ }^{5}$

DOI: https://doi.org/10.31692/2358-9728.VIICOINTERPDVL.0325

\section{RESUMO}

Neste artigo faremos uma análise sobre as implicações da gestão democrática na construção do Projeto Político Pedagógico (PPP), sua relação com o Conselho Escolar e os reflexos da pandemia causada pelo COVID-19. Como fundamentação teórica tomamos como subsídios as contribuições de Botler e Tavares, (2007) no que se referem a organização do Conselho Escolar. Analisaremos as implicações da Gestão com o Conselho Escolar (ADRIÃO; CAMARGO, 2003), bem como, a correlação entre participação e autonomia (AGUIAR et. al., 2009) dos atores sociais envolvidos nas tomadas de decisões. Problematizaremos a democracia no âmbito escolar com base na autonomia e nos ideais de cada membro da comunidade que participa da escola direta ou indiretamente, ou seja, independente de sua orientação religiosa, de suas escolhas pessoais, gênero, raça etc., a comunidade deverá ser ouvida com direito a participação ativa nas tomadas de decisões por meio do Conselho Escolar. Portanto, essa liberdade democrática é vista como um eixo orientador para modificação da realidade existente, sendo assim, tudo é feito em prol dos interesses de todos e neste segmento a gestão analisada colabora para que isso aconteça. A metodologia se deu a partir de uma entrevista com uma Gestora da escola, de forma remota; um levantamento de dados sobre o Conselho Escolar e uma análise no PPP da Escola, do qual tivemos total acesso. Os resultados apontaram que embora a Gestora atue de forma democrática, há uma resistência da comunidade em participar ativamente das atividades democráticas na atuação do

\footnotetext{
${ }^{1}$ Pedagogo, Graduando em Letras Libras, Universidade Federal de Pernambuco/UFPE, roniero.diodato@ufpe.br ${ }^{2}$ Pedagoga, Graduanda em Letras Libras, Centro Universitário Leonardo Da Vinci/UNIASSELVI, jackeline.libras@gmail.com

${ }^{3}$ Pedagoga, Graduanda em Letras Libras, Centro Universitário Leonardo Da Vinci/UNIASSELVI, dry.patricia@ hotmail.com

${ }^{4}$ Pedagogo, Graduando em Letras Libras, Universidade Federal da Paraíba/UFPB, lucio.costa@ academico.ufpb.br ${ }^{5}$ Mestranda em Educação, Programa de Pós-Graduação em Educação/Universidade Federal de Pernambuco, suzanatemudo@ hotmail.com
} 


\title{
IMPLICAÇÕES DA GESTÃO DEMOCRÁTICA NA CONSTRUÇÃO DO
}

Conselho Escolar, tanto da elaboração e acompanhamento do PPP. O fato se tornou comum devido ao insolamento social, instaurado no decorrer dapandemia, no entanto, a gestora afirma que de alguma forma tentou estreitar os laços com a comunidade no intuito de contribuir para redução dos danos causados durante a pandemia. De fato, cabe ao gestor concretizar a gestão democrática no sentido de impulsionar a quebra de uma gestão verticalizada, além de promover na escola uma ação coletiva e democrática na elaboração de projetos pedagógicos que visam englobar toda a comunidade escolar. Constatamos que quanto mais assídua for a participação de todos os segmentos, maior será a probabilidade de alcançarmos uma educação de qualidade, visando à formação de cidadãos críticos, participativos e dispostos a lutar pelos seus direitos.

Palavras-Chave: Gestão Democrática, Conselho Escolar, Projeto Político Pedagógico, Pandemia.

\section{RESUMEN}

En este artículo analizaremos las implicaciones de la gestión democrática en la construcción del Proyecto Político Pedagógico (PPP), su relación con el Consejo Escolar y los reflejos de la pandemia provocada por COVID-19. Como fundamento teórico tomamos como aportaciones las aportaciones de Botler y Tavares, (2007) sobre la organización del Consejo Escolar. Analizaremos las implicaciones de la Gestión con el Consejo Escolar (ADRIÃO; CAMARGO, 2003), así como la correlación entre participación y autonomía (AGUIAR et al., 2009) de los actores sociales involucrados en la toma de decisiones. Problematizaremos la democracia en el ámbito escolar en base a la autonomía e ideales de cada miembro de la comunidad que participa en la escuela directa o indirectamente, es decir, independientemente de su orientación religiosa, elecciones personales, género, raza, etc., la comunidad debe ser escuchados con derecho a la participación activa en la toma de decisiones a través del Consejo Escolar. Por tanto, esta libertad democrática se ve como un eje rector para modificar la realidad existente, por tanto, todo se hace en interés de todos y en este segmento la dirección analizada colabora para que esto suceda. La metodología se basó en una entrevista con un director de la escuela, de forma remota; un relevamiento de datos sobre el Consejo Escolar y un análisis en el PPP del Colegio, del que tuvimos pleno acceso. Los resultados mostraron que si bien el Gerente actúa de manera democrática, existe resistencia de la comunidad a participar activamente en las actividades democráticas en el desempeño del Consejo Escolar, tanto en la preparación como en el seguimiento del PPP. El hecho se volvió común debido a la insolación social, instaurada durante la pandemia, sin embargo, la gerente dice que de alguna manera trató de fortalecer los lazos con la comunidad con el fin de contribuir a reducir los daños ocasionados durante la pandemia. De hecho, le corresponde al directivo implementar una gestión democrática con el fin de propiciar la ruptura de una gestión verticalizada, además de promover una acción colectiva y democrática en la escuela en la elaboración de proyectos pedagógicos que pretendan abarcar a toda la comunidad escolar. Encontramos que cuanto más asidua la participación de todos los segmentos, mayor es la probabilidad de lograr una educación de calidad, orientada a la formación de ciudadanos críticos, participativos y dispuestos a luchar por sus derechos.

Palabras clave: Gestión Democrática, Consejo Escolar, Proyecto Político Pedagógico, Pandemia.

\begin{abstract}
In this article we will analyze the implications of democratic management in the construction of the Political Pedagogical Project (PPP), its relationship with the School Council and the reflexes of the pandemic caused by COVID-19. As a theoretical foundation we take as contributions the contributions of Botler and Tavares, (2007) regarding the organization of the School Council. We will analyze the implications of Management with the School Council (ADRIÃO; CAMARGO, 2003), as well as the correlation between participation and autonomy (AGUIAR et al., 2009) of the social actors involved in decision making. We will problematize democracy in the school environment based on the autonomy and ideals of each member of the community that participates in the school directly or indirectly, that is, regardless of their religious orientation, personal choices, gender, race etc., the community should be heard with the right to active participation in decision-making through the School Council. Therefore, this democratic freedom is seen as a guiding axis for modifying the existing reality, therefore, everything is done in the interests of everyone and in this segment the management analyzed collaborates to make this happen. The methodology was based on an interview with a school manager, remotely; a survey of data on the School Council and an analysis in the School's PPP, from which we had full access. The results showed that although the Manager acts in a democratic manner, there is resistance from the
\end{abstract}


community to actively participate in democratic activities in the performance of the School Council, both in the preparation and monitoring of the PPP. The fact became common due to the social insolation, established during the pandemic, however, the manager says that somehow she tried to strengthen ties with the community in order to contribute to reducing the damage caused during the pandemic. In fact, it is up to the manager to implement democratic management in order to encourage the breakdown of a verticalized management, in addition to promoting a collective and democratic action in the school in the elaboration of pedagogical projects that aim to encompass the entire school community. We found that the more assiduous the participation of all segments, the greater the probability of achieving a quality education, aiming at the formation of critical, participative and willing citizens to fight for their rights.

Keywords: Democratic Management, School Council, Political Pedagogical Project, Pandemic.

\section{INTRODUÇÃO}

Conforme artigo 205 da Constituição Federal de 1988 a educação é um direito de todos e dever do estado e da família e sua promoção deverá ser incentivada com a colaboração da sociedade, visando ao pleno desenvolvimento da pessoa, seu preparo para o exercício da cidadania (BRASIL, 1988). Cabe ao Estado e em conjunto com a sociedade civil organizada, representada pelas diversas instituições sociais, a responsabilidade de educar e formar os cidadãos para que possam atuar de forma consciente no compartilhamento do poder decisório do Estado. É relevante destacar que este lugar, de tomada de decisão, é privilegiado para todo cidadão tendo como reflexo o exercício concreto da cidadania na construção e no avanço dos processos democráticos de uma sociedade.

Nessa perspectiva cabe ao gestor escolar concretizar a gestão democrática no sentido de impulsionar a quebra de uma gestão horizontalizada que limita a participação dos diversos atores sociais que compõem o corpo da escola. Dessa forma, é possível garantir uma ação coletiva e democrática na elaboração de projetos pedagógicos que visam englobar toda a comunidade.

Face ao exposto, o presente estudo tem como objetivo compreender as implicações da gestão democrática na construção do Projeto Político Pedagógico (PPP) e os reflexos trazidos pela pandemia. Abordaremos as questões relacionadas a gestão democrática, as relações interpessoais entre professores, alunos, funcionários e comunidade externa.

Para consolidarmos o processo desta relação, faremos uma análise do Projeto Político Pedagógico (PPP/2019) e do Conselho Escolar - ativo desde a sua fundação no ano 2000 - e como ocorre o diálogo entre estes segmentos. Além disso, analisaremos as questões entre o que foi planejado e o que não foi possível executar, em decorrência do estado de crise que se instaurou por conta da pandemia causada pelo Covid- 19 e que impôs o isolamento social em virtude da alta taxa de transmissão e de letalidade do vírus que ocasionou no fechamento das 


\section{IMPLICAÇÕES DA GESTÃO DEMOCRÁTICA NA CONSTRUÇÃO DO}

escolas impactando, portanto, nos processos de ensino e aprendizagens.

Nesse contexto de incertezas a gestão escolar, os coordenadores, os professores e os alunos encontram-se diante de um novo desafio: o uso das tecnologias digitais no contexto educacional, bem como, no processo de ensino aprendizegem. Neste novo cenário todos que estão envolvidos com a educação encontram-se diante desta problemática: como por em prática as novas estratégias de ensino que possibilitem que crianças e adolescentes de todo país acessem os conteúdos escolares, por meio de atividades remotas, visando reduzir os impactos negativos na vida escolar dos alunos e cumprimento do ano letivo?

Nesse sentido, torna-se necessária, uma reflexão sobre as novas formas de gestão orientadas sobre os princípios da gestão democrática, que permitam à comunidade escolar, mesmo a diante de um contexto de pandemia, a participação nos processos decisórios através dos instrumentos tecnológicos que possam auxiliar e também assegurar uma gestão escolar democrática.

Para nossa reflexão teórica tomamos como subsídios as contribuições de Botler e Tavares (2007) no que se referem a organização do Conselho Escolar; as implicações da gestão com o Conselho Escolar (ADRIÃO; CAMARGO, 2003), entre outros que iremos relacionar com temática de nossa pesquisa.

Com o intuito de responder nossas inquietações, foi feita uma pesquisa de caráter qualitativo, compreendida por Triviños (1987) como pesquisa de campo, cuja finalidade é a coleta de dados no ambiente onde acontecem os fatos.

Tendo em vista a pandemia instaurada devido o COVID-19, não foi possível ir à campo, no entanto, elaboramos e aplicamos uma entrevista semiestruturada, de forma remota, com a gestora, identificada como G-1, de uma escola da rede municipal da cidade do Recife no Estado de Pernambuco. Esta escola está localizada na "RPA1" (nomeclatura utilizada na organização das escolas que estão divididas por Regiões Político Adminisrativas, ou seja as RPA). É importante frisar que a pedido da gestora, seus dados serão preservados, bem como, a identificação da escola e em respeito a esta solicitação as informações sobre a escola serão mantidas em sigilo.

Sobre a relação escola/comunidade na construção de bons vínculos entre professores, alunos, pais e/ou responsáveis identificamos a realização, durante três vezes ao ano, de reuniões de pais e mestres convocadas pelo Conselho Escolar para que os familiares dos educandos possam acompanhar o desempenho escolar dos seus filhos(as). O referido Conselho Escolar é composto por todos os segmentos que conjungam a comunidade escolar como gestora, professores, funcionários, alunos e comunidade externa. É importante frisar que o Coselho 
Escolar continua atuante e com eleições realizadas a cada dois anos garantido a efetivação de uma gestão de democrática na escola.

Identificamos também a existência de um Conselho Pedagógico formado apenas por professores com intuito de promover, para o ano seguinte, os alunos que se destacaram ou reter aqueles que se encontram abaixo do nível esperado ou até mesmo inseri-los em programas nacionais e internacionais promovidos pelo governo e que a escola está vinculada.

No decorrer da pesquisa, identificamos que na escola há vestígios de uma gestão democrática, porém existem lacunas a serem preenchidas por parte de um dos segmentos considerados relevantes para sua efetivação, a comunidade.

Constatamos que quanto maior e mais qualificada a participação de todos os segmentos, maior será a probabilidade de alcançarmos uma educação de qualidade, visando à formação de cidadãos críticos, participativos e dispostos a lutar pelos seus direitos.

O resultado de uma educação de qualidade se reflete na atuação dos gestores educacionais visando a promoção da participação de todos os atores sociais envolvidos no processo de ensino aprendizagem. Em suma, do currículo às decisões burocráticas, a atuação da comunidade escolar é relevante para consolidar práticas de gestão consideradas democráticas.

A seguir faremos uma discussão teórica sobre os princiapais conceitos elencados neste artigo. Na sequência, apontaremos a metodologia adotada seguida das análises e discussão dos resultados. Por fim, nas conclusões promoveremos o debate de como repensar práticas de gestão que consideramos democráticas.

\section{FUNDAMENTAÇÃO TEÓRICA}

"Todo poder emana do povo, que o exerce por meio de representantes eleitos ou diretamente" (BRASIL, 1988, p.8). Essa máxima nos remete a refletir sobre a prática da democracia no âmbito educacional e a possível relação e participação dos atores sociais da escola nas tomadas de decisões da gestão escolar. Cabe ao gestor concretizar a gestão democrática no sentido de impulsionar a quebra de uma gestão verticalizada, além de promover na escola uma ação coletiva e democrática na elaboração de projetos pedagógicos que visam englobar toda a comunidade.

Consideramos como gestão democrática a participação ativa de toda comunidade escolar, tendo como base o princípio da autonomia. Em outras palavras, é necessário que haja a participação de todos os segmentos envolvidos na organização da escola, inclusive a comunidade externa. Botler e Tavares (2007 p.156) consideram que "a concepção de 


\section{IMPLICAÇÕES DA GESTÃO DEMOCRÁTICA NA CONSTRUÇÃO DO}

autonomia, portanto, se agregam os valores e os ideais que a comunidade escolar defende, e por isso mesmo, definem qual autonomia a escola define para si como organização”. Em direção a essa concepção, apesar desta autonomia ser ameaçada mediante o novo formato de governo, com o fechamento de pastas ministeriais, por exemplo, a paraticipação da comunidade em torno da escola é fundamental para o execício da escuta e atendimento das suas necessidades.

Compreendemos a partir dessa perspectiva que a democracia está aliada à autonomia no sentido de por em prática a participação da comunidade escolar, o que há em comum entre os interesses desta comunidade e da gestão. Como princípio de democracia, concordamos com Sakata e Lima (2018),

O conceito de democracia é complexo, transcendental e está presente na sociedade desde tempos remotos. Etimologicamente, o termo democracia vem do grego demokratía, governo do povo. Governo em que o povo exerce a soberania, direta ou indiretamente4. Sua definição, como forma de Estado e sob um viés histórico, depende do tipo de sociedade em que está inserido e, principalmente, de quem é considerado apto a participar das decisões (SAKATA; LIMA 2018 p. 2).

Justifica-se portanto, a relevância da formação do Conselho Escolar representado por pais, alunos, docentes e gestores escolares e a partir dele a escola deve estabelecer regras transparentes e democráticas que determinem a participação de todos/as, inclusive no que se rerefe a eleição dos seus membros. Sobre a eleição, esta precisa estar em consonância com o Regimento que regula o funcionamento do Conselho Municipal de Educação do Recife - CME. Nesse documento constitui-se como Conselho Municipal de Educação do Recif,e órgão normativo, deliberativo e consultivo do Sistema Municipal de Ensino do Recife, sendo-lhe assegurados caráter público, constituição paritária e democrática e autonomia no exercício de suas competências (RECIFE, 2014).

Para Adrião e Camargo (2003 p.5) "o Conselho Escolar era visto como um dos meios para a democratização das relações de poder no interior da escola, marcadamente hierarquizada e centralizada na figura do diretor". Com o passar do tempo surgiram novas demandas sociais, que reivindicavam, por meio dos movimentos sociais, um país mais justo e igualitário. A partir do movimento de luta em prol da democracia durante o regime militar, surgiu a necessidade de uma reformulação na organização do Conselho Escolar, de uma perspectiva centralizada à uma abordagem democrática na qual todos possam participar exercendo sua autonomia nas tomadas de decisões.

A partir dessas mudanças permitiu-se as primeiras ações democráticas no campo da educação, despertando no estudante a criticidade e a capacidade de analisar os fatos 
ocorridos em seu meio e a vontade de modificar a realidade existente, tendo como princípio norteador a democracia. Neste sentido, Aguiar et. al. (2009) traz a seguinte contribuição:

A participação e autonomia são elementos indispensáveis à gestão democrática, tornando-se condições para o estabelecimento da estrutura organizacional da escola, que busca uma nova prática educativa respaldada nas relações curriculares, assentada nos eixos de interação, cooperação e solidariedade (AGUIAR et. al, 2009 p. 86).

Com base nos autores supracitados, a autonomia está baseada nos valores e nos ideais de cada membro da comunidade que participa da escola direta ou indiretamente, ou seja, independente de sua orientação religiosa, de suas escolhas pessoais, gênero, raça etc., a comunidade é ouvida e participa ativamente nas tomadas de decisões por meio do Conselho Escolar. Portanto, essa liberdade democrática é vista como um eixo orientador para modificação da realidade existente, sendo assim, tudo é feito em prol dos interesses de todos e neste segmento a gestão colabora para que isso aconteça.

Para reforçar nossa reflexão sobre a autonomia e o fortalecimento da escola, abordamos Paro (1998) ao afirma que

na medida em que se consegue a participação de todos os setores da escola educadores, alunos, funcionários e pais - nas decisões sobre os objetivos e funcionamento da escola, haverá melhores condições para pressionar os escalões superiores a adotar a escola de autonomia e de recursos, pois é muito mais difícil dizer "não", quando a reivindicação não for de uma pessoa, mas de um grupo (PARO, 1998, p. 12).

Como vimos, uma escola realmente democrática tem como compromisso maior ouvir todas e todos os envolvidos no processo das tomadas de decisões. É relevante que a gestão ouça os anseios da comunidade escolar de maneira que essas decisões sejam horizontalizadas e que todos tenham igual acesso as informações.

Esse processo de participação possibilita aos sujeitos o exercício da democracia, pois toda a construção coletiva requer que todos sejam ouvidos, tendo o direito de se expressarem e que haja respeito na fala de cada um. Em suma, em todo processo de gestão democrática, quanto maior e mais qualificada a participação de todos os segmentos, maior será a possibilidade de alcançar os objetivos previstos em relação ao que está sendo elaborado coletivamente.

Concordamos com Marques (2005) e suas contribuições sobre o Conseslho Escolar:

o Conselho Escolar pode ser um espaço de construção de uma escola voltada para os interesses da maioria da poupualulação brasileira, que pode influir na educação que lhe é oferecida. Os Conselhos Escolares podem representar um 


\title{
IMPLICAÇÕES DA GESTÃO DEMOCRÁTICA NA CONSTRUÇÃO DO
}

instrumento de aprendizado democrático, que se efetivará a partir da transformação da prática escolar "cotidiana", no enfrentamento de posturas autoritárias, podendo, assim, ter papel fundamental na construção de uma cultura democrástica nas escolas públicas (MARQUES, 2005 p. 96).

A gestão ao assumir um papel democrático vai de encontro a Costituição de 1988, fazendo valer o direito de escolha do cidadão. Além disso, encontramos também no Plano Nacional de Educação (PNE) dados sobre a democratização da gestão no ensino público como estabelecimentos oficiais que seguem os princípios da participação dos profissionais da educação na elaboração de projetos pedagógicos que compõem a escola e a participação da comunidade escolar através dos seus Conselhos Escolares (BRASIL, 2000).

Para elaboração desses projetos, o planejamento seja ele a curto, médio ou longo prazo é fundamental para a efetivação da prática pedagógica. O planejamento é um processo de racionalização, organização e coordenação do trabalho e ação docente, articulando a atividade escolar com ênfase no contexto social do qual a escola está inserido. Dito isto, espera-se que nas escolas públicas, tanto professores como alunos interajam entre si, pois tudo o que acontece no ambiente escolar possui influências econômicas, políticas e culturais que caracterizam a sociedade de classe (LIBÂNEO, 2013).

Tendo como base o planejamento, uma vez discutido em conjunto com a comunidade escolar e que está diretamente relacionado as práticas curriculares, Sakata e Lima (2018) afirma que

\begin{abstract}
Neste prisma, o âmbito educacional é uma das arenas destas práticas teóricas. Estudá-las nos traz consciência de como está sendo desenvolvida a gestão democrática escolar, quais seus princípios e o que a fundamenta. A compreensão aprofundada das teorias que discorrem sobre a democracia é um dos pilares que podem auxiliar a nossa ação enquanto educadores, no sentido de nos aproximarmos de uma gestão democrática (SAKATA; LIMA, 2018).
\end{abstract}

No que se refere as práticas curriculares, estas devem ser cumpridas através do Projeto Político Pedagógico da escola com base nas Leis estabelecidas como a Lei de Diretrizes e Bases n 9394 (BRASIL, 1996) e a Constituição de 1988. É relevate que sejam postas em prática através da interação com base nos projetos elaborados pela gestão, coordenação e professores, consequentemente trabalhados em sala de aula.

Esta relação entre os atores sociais da escola é relevante, pois nas palavras de Gadotti (1999),

O projeto da escola não é responsabilidade apenas de sua direção. Ao 
contrário, numa gestão democrática, a direção é escolhida a partir do reconhecimento da competência e da liderança de alguém capaz de executar um projeto coletivo. A escola, nesse caso, escolhe primeiro um projeto e depois essa pessoa que pode executá-lo. Assim realizada, a eleição de um diretor, de uma diretora, possibilita a escolha de um projeto políticopedagógico para a escola. Ao se eleger um diretor de escola o que se está elegendo é um projeto para a escola. Na escolha do diretor ou da diretora percebe-se já o quanto o seu projeto é político (GADOTTI, 1999 p. 2).

Mediante a pespectiva de Gadotti (1999), para a escola ter a frente uma gestão que atenda as especificidades da comundide escolar, é necessário que se fale a linguagem da comunidade envolvida, que se leve em consideração suas escolhas tornando o processo democrático claro e que sejam levadas em consideração todas as propostas dos que estão envolvidos.

Dessa forma consideramos válidas as contribuições dos autores estudados, pois pudemos relacioná-las com êxito às reflexões trazidas neste estudo.

No ítem a seguir, apontaremos a metodologia utilizada para o tratamento dos dados e levantamento das discussões.

\section{METODOLOGIA}

Com o intuito de responder nossas inquietações foi feita uma pesquisa, de caráter qualitativo, compreendida por Triviños (1987) como pesquisa de campo, cuja finalidade é a coleta de dados no ambiente onde acontecem os fatos.

Tendo em vista a pandemia instaurada devido o COVID-19, não foi possível ir à campo, dessa forma, elaboramos e aplicamos uma entrevista semiestruturada de forma remota com uma gestora de uma escola da rede municipal da cidade do Recife identificada como "G1". Esta escola está localizada na "RPA1" (nomeclatura utilizada na organização das escolas municipais que estão divididas por Regiões Político Adminisrativas, ou seja, as RPA). É importante frisar que a pedido da gestora, seus dados serão preservados, bem como, a identificação da escola e em respeito a esta solicitação as informações sobre a escola e sobre a gestora serão mantidas em sigilo.

Durante a entrevista, realizada no mês de agosto do ano corrente, com duração de uma hora, questionamos a gestora sobre sua atuação e os desafios encontrados relacionados à prática da gestão democrática. Por ser um dos membros do Conselho Escolar, aproveitamos o ensejo e fizemos alguns questionamentos no tocante a atuação deste órgão junto a gestão na tomada de decisões.

Indagamos sobre sua atuação, enquanto gestora e do planejamento pedagógico feito no 


\section{IMPLICAÇÕES DA GESTÃO DEMOCRÁTICA NA CONSTRUÇÃO DO}

ano anterior, especificamente para execução ano de 2020. A entrevista foi conduzida a partir das seguintes perguntas norteadoras: como foi a relação com a comunidade externa representada no Conselho Escolar para tomadas de decisões? Como ocorreu o planejamento pedagógico tendo em vista o ano letivo de 2020? Quais os reflexos da pandemia frente ao que foi planejado e, possivelmente, não executado devido a pandemia e de que maneira a comunidade escolar manteve relação com a gestão e com a escola, mesmo em tempos remotos?

Além da entrevista, também foi feita uma análise no Projeto Político Pedagógico/PPP da Escola (enviado pela gestão, via e-mail) e levantamento de dados (durante a entrevista) sobre a constituição e continuidade do Conselho Escolar e suas intervenções na elaboração do planejamento para o ano letivo de 2020.

Vale ressaltar que o Projeto Político Pedagógico da Escola pesquisada, foi enviado com autorização do Conselho Escolar. Esclarecemos também que o objetivo de nossa pesqusia é levantar a discussão sobre como o Estado de Pernambuco atua no sentido de subsidiar o trabalho da gestão escolar e promover a autonomia da escola.

Destacamos ainda que o Conselho Escolar está ciente de que as informações serão mantidas em sigilo e os dados da escola serão preservados.

\section{RESULTADOS E DISCUSSÃO}

\section{O olhar da gestão}

Com base nos estudos realizados observamos algumas características de nossa pesquisa em consonância com a discussão teórica vista ao longo desse trabalho e que merecem nossas análises e considerações.

Durante a entrevista com a gestora da escola, percebemos que em sua gestão há uma dedicação no que ser refere a prática da gestão democrática.

Ela afirma estar envolvida com o corpo docente e todos os atores sociais, tantos os membros da comunidade escolar, como a comunidade externa, embora a comunidade não seja tão atuante como se esperava. Mesmo diante desse desafio, a gestora se dispõe a cumprir o que se encontra na Lei de Diretrizes e Basesa da Educação nº 9394 (BRASIL, 1996) enquanto política de Estado.

Interrogada sobre o planejamento anual, em sua fala percebemos o esforço em aproximar a comunidade externa nas tomadas de decisões.

Para que meu trabalho faça sentido aqui na escola é preciso envolver toda a comunidade; convidá-la para as eleições e participação no Conselho Escolar, 
na elaboração do PPP e manter um diálogo permanente (G1).

No decorrer da entrevista, perguntamos como ocorreu o planejamento para o ano letivo de 2020 e os reflexos de sua execução, tendo em vista a pandemida do COVID-19.

A gestora relatou que tudo transcorreu (em 2019) como nos anos anteriores. Ou seja, inicialmente os professores, coordenadores e a gestão organizaram um planejamento piloto, que foi apresentado a comunidade interna/externa representada pelo Conselho Escolar. Como é de praxe, após as contribuições do Conselho Escolar foram feitas reuniões com o intuito preencher algumas lacunas caso ocorram no decorrer do processo de implementação. Segundo a gestora, no mês de março do ano corrente, foi feita a primeira reunião com o Conselho Escolar para deliberar as atividades para os demais setores da escola, porém com a chegada da pandemia e o fechamento da escola, o processo teve que ser interrompido.

Nas palavras da gestora ela afirma ter ficado angustiada pela forma brusca com que o processo fora interrompido:

foi uma surpresa para todos nós, e claro, que nós não estávamos esperando uma coisa dessas acontecer. No início do insolamento tínhamos, quero dizer eu e todos os professores, esperança em voltar para escola, mas devido o agravamento da situação, tudo ficou estagnado. Tempos depois nos reunimos, desta vez, on-line, com o Conselho Escolar e decidimos, que de alguma forma, ainda não sabíamos como, que deveríamos nos aproximar da comunidade escolar para saber o que a escola poderia fazer naquele momento (G1).

Percebemos na fala da gestora, além de uma preocupação com a comunidade escolar, uma tentativa de pôr em prática a gestão democrática mesmo que de forma remota, considedara como a maneira mais adequada de manter o contato social durante esse tempo de pandemia. Durante a entrevista a gestora afirmou que todas as decisões para suspensão das atividades foram acordadas, embora tenha se obedecido o Decreto Estadual nº 49.055 que Sistematiza as regras relativas às medidas temporárias para enfrentamento da emergência de saúde pública de importância internacional decorrente do novo coronavírus, conforme previsto na Lei Federal no 13.979, de 6 de fevereiro de 2020 (PERNAMBUCO, 2020).

Quanto aos recursos financeiros, a gestora afirmou que para o ano letivo de 2020 estão sendo direcionados a medida que a gestão municipal determina até que voltem as aulas presenciais, no entanto, afirmou que nos anos anteriores houve investimento a partir do que foi planejado e decidido pelo Conselhor Escolar. É relevante frisar que a gestora não entrou em 


\section{IMPLICAÇÕES DA GESTÃO DEMOCRÁTICA NA CONSTRUÇÃO DO}

detalhes sobre o que havia planejado, nem em quem foram investidos os recursos recebidos nos anos anteriores.

Outro destaque que a gestra frisou foi sobre a possibilidade da volta as aulas de forma remota. Durante as reuniões os professores afirmaram que não estavam preparados para este novo formato de educação, no entanto, com o apoio da gestão e coordenação pedagógica, foi possível traçar novas estratégias para implementar o ensino remoto na escola.

No primeiro momento houve uma resistência, principalmente dos pais e famíliares dos estudantes, pois alegaram não ter recursos tecnológicos suficientes, como notebook, tables ou mesmo celulares e internet suficiente para manterem seus filhos nessas condições de ensino" (G1).

Sobre a deliberação das aulas remotas, a gestora afirma que foi uma exigência da Secretaria de Educação e cabia aos gestores, supervisores e corpo docente se reorganizaem e pensarem nos planos de aula para esse novo formato.

Diante desse cenário ficou evidente a falta de recursos tecnológicos dos estudantes e o quanto os reflexos da Pandemia atingiu toda população, pois além de sofrerem sem o suporte necessário do Minstério da Saúde, precisariam manter seus filhos estudanto para não haver prejuízo no ano letivo. Apesar disso, a gestora afirmou que iniciaram um trabalho remoto, embora a percentagem de participação tenha sido ínfima para o esperado.

\section{Aspectos sobre o Projeto Político Pedagógico e o Conselho Escolar}

Partindo da leitura e análise do Projeto Político Pedagógico (PPP) do ano de 2019, do qual tivemos total acesso, sua reformulação ocorre a cada ano, na busca de identificar e solucionar os possíveis problemas da escola. O PPP tem como meta:

assegurar aos seus alunos uma escola de qualidade ensino, contemplar os interesses prioritários de todos os segmentos da escola, estabelecer um diálogo aberto com a comunidade, conscientizar os mesmos de seus deveres e direitos em busca de uma sociedade igualitária (PPP, 2014).

De acordo com este documento analisado a cada bimestre a escola realiza reuniões de pais e mestres, para tratar de temas como, evasão escolar, ensino e aprendizagem e questões em torno da indisciplina. Portanto, podemos afirmar que a construção coletiva do PPP possibilita a sustentação e legitimação dos projetos escolares. Quanto maior e mais qualificada a participação de todos os segmentos, maior será a probabilidade da escola alcançar suas metas e os objetivos traçados. Dessa forma, possibilitará aos membros envolvidos neste processo, o 
exercício da democracia.

Conforme a fala da gestora, não foi possível executar o PPP como era previsto dedivo a Pandemia instaurada desde o mês de março. Ocorre que o Conselho Escolar decidiu reajustar e adaptá-lo para a nova realiade. A gestora não definiu como seria esta adaptação. Com base na entrevista percebemos uma preocupação com o bem estar da comunidade escolar e com a possibilidade da volta as aulas de modo presencial. A gestora afirmou que fará um levantamento do estado dos estudantes, familiares e corpo docente e tentará, juntamente com o Conselho Escolar para adaptar o PPP para esta nova realidade.

No que se refere ao Conselho Escolar, último objeto analisado, como já foi dito anteriormente é ativo e mantido por meio de eleições democráticas. Embora a gestora afirme que a comunidade não atua como deveria dentro do Conselho, a oportunidade é concedida igualmente a todos os segmentos. Esse é um dos desafios: "fazer com que a comunidade participe ativamente no processo da democracia de maneira ativa excercendo sua cidadania" (G1).

Como vimos, o Conselho Escolar tem sido um dos setores da escola na qual a democracia tem se mostrado presente e atuante; contribuindo para as tomadas de decisões no espaço escolar e uma esfera privilegiada no qual os membros da comunidade possam ser identificados, ouvidos e respeitados.

A relação entre as três esferas analisadas pressupõe uma gestão democrática atuante, embora haja algumas falhas, como por exemplo, o desinteresse parcial da comunidade. Não obstante, no PPP encontramos dados que definem as metas, objetivos e busca da participação de todos os segmentos na tomada de decisão. Sendo assim, os resultados apontam que há uma relação harmônica entre os instrumentos analisados.

Consideramos o PPP como o ponto fulcral para um bom desenvolvimento da escola. É relevante que esse documento atenda as especificidades de toda comunidade escolar, pensandose inclusive nas questões de acessibilidade para os alunos com deficiência.

Sobre os aspectos relacionados aos alunos com deficência a gestora nos informou que está sendo feito um projeto para atender a este público, no entanto não especificou. Segundo sua fala:

o Conselho Escolar está fazendo um levantamento de todos os estudantes para tenter, de alguma forma tentar atender as necessidades deles. Temos alunos surdos, autistas e cegos, mas ainda não temos subsídios necessários para atende-los (G1). 


\section{IMPLICAÇÕES DA GESTÃO DEMOCRÁTICA NA CONSTRUÇÃO DO}

Em seu último depoimento percebemos uma preocupação com o corpo discente principalmente sobre a especificidades de cada estudante. Percebemos também que estão sendo tomadas decisões para o atendimento necessário de acordo com a deficiência dos alunos.

Para não haver fuga da temática e do objetivo deste artigo, não aprofundaremos as questões relacionadas aos alunos com deficiência.

\section{CONCLUSÕES}

O resultado de uma educação de qualidade se reflete na atuação dos gestores educacionais visando a promoção da participação de todos os atores sociais envolvidos no processo de ensino aprendizagem. Do currículo às decisões burocráticas, a atuação da comunidade escolar é relevante para consolidar práticas de gestão consideradas democráticas.

Entendemos como gestão democrática um conceito amplo, pois é preciso levar em consideração a participação de todos os atores sociais envolvidos no âmbito escolar. Com base nos estudos realizados observamos algumas características de nossa pesquisa em consonância com a discussão teórica vista ao longo desse trabalho e que fizeram parte de nossas análises e considerações.

No decorrer da pesquisa identificamos que na escola há vestígios de uma gestão democrática, porém existem lacunas a serem preenchidas por parte de um dos segmentos considerados relevantes para sua efetivação, a comunidade. Essa afirmação se refletiu na fala da gestora ao afirmar que embora atue democraticamente, não há interesse da comunidade em participar como elemento ativo na gestão.

Partindo do olhar da gestão identificamos uma dedicação no que ser refere a prática da gestão democrática. Pois, envolvida com o corpo docente e todos os atores sociais, tanto os membros da comunidade escolar, quanto a comunidade externa são convocados para partilharem a gestão democrática.

Sobre os aspectos relacionados ao Projeto Político Pedagógico da Escola, costruído de forma coletiva, possibilita a sustentação e legitimação dos projetos escolares. Quanto maior e mais qualificada a participação de todos os segmentos, maior será a probabilidade da escola alcançar suas metas e os objetivos traçados. Dessa forma, possibilitará aos membros envolvidos neste processo, o exercício da democracia.

Constatamos que quanto maior e mais qualificada a participação de todos os segmentos, maior será a probabilidade de alcançarmos uma educação de qualidade, visando à formação de cidadãos críticos, participativos e dispostos a lutar pelos seus direitos.

Não pretendemos encerrar, nesse espaço, a discussão a respeito da gestão democrática. 
Com base no que foi analisado pretendemos levantar novos argumentos que nos possibilite repensar práticas de gestão, que consideramos democráticas e encontrar meios de atrair a comunidade escolar para atuar como sujeitos ativos no âmbito escolar.

\section{REFERÊNCIAS}

ADRIÃO, T.: CAMARGO, Rubens Barbosa de. Princípios e processos da gestão democrática: implicações para os conselhos escolares. Chão da Escola, Curitiba, v. nº 02, 2003.

AGUIAR, M. C. C.; MACHADO, L. B.; SANTIAGO, M E; BARBOSA, M. R.; BARBOSA, M. L. F. F. Gestão Democrática, elementos conceituais e a democratização do acesso, permanência e sucesso escolar. In: Laêda Bezerra Machado; Eliete Santiago. (Org.). Políticas e Gestão da Educação Básica. 1ªed. Recife: Editora Universitária da UFPE, 2009, v. 1.

BRASIL. Constituição Federativa do Brasil. Brasília Senado Federal: Centro Gráfico, 1988. Disponível https://www2.senado.leg.br/bdsf/bitstream/handle/id/518231/CF88_Livro_EC91_2016.pdf?se quence $=1$. Acesso em 15 set. 2020.

BRASIL. Diretrizes e Bases da Educação Nacional. Lei nº 9.394, de 20 de dezembro de 1996. Disponível em http://www.planalto.gov.br/ccivil_03/Leis/L9394.htm. Acesso em 24 mar. 2020.

BRASIL. Ministério da Educação e Cultura. Plano Nacional de Educação. Brasília, 2000. Disponível em http://portal.mec.gov.br/arquivos/pdf/pne.pdf. Acesso em 12 de nov. 2020.

BOTLER, Alice e TAVARES, Marina. A proposição de normas na organização escolar: valores construídos ou determinados? Recife: Ed. UFPE, 2007.

MARQUES, Luciana Rosa. A descentralização da gestão escolar e formação de uma cultura democrática nas escolas públicas. 2005, $288 \mathrm{f}$. Tese (Doutorado em Sociologia) Uniersidade Federal de Pernambuco, Recife, 2005. Disponível em https://repositorio.ufpe.br/bitstream/123456789/9709/1/arquivo9273 1.pdf. Acesso em 10 ago. 2020.

GADOTTI, Moacir. O Projeto Político-Pedagógico da Escola na erspectiva de uma $\begin{array}{llllll}\text { Educação para } & \text { a } & \text { Cidadania. } & 1999 . & \text { Disponível } & \text { em }\end{array}$ http://files.professorivo.webnode.pt/200000095-f1511f24b6/PPP\%20\%20Moacir\%20Gadotti.pdf. Acesso em 11 out. 2020.

LIBÂNEO, Carlos José. O planejamento escolar. 2013. Disponível em https://edisciplinas.usp.br/pluginfile.php/4452090/mod_resource/content/2/Planejamento\%20\%20Lib\%C3\%A2neo.pdf. Acesso em 01 dez. 2019.

PERNAMBUCO. Decreto 49.055 de 31 de maio de 2020. Sistematiza as regras relativas às medidas temporárias para enfrentamento da emergência de saúde pública de importância internacional decorrente do novo coronavírus. Recife/PE, 2020.

PARO, Vitor Henrique. Políticas educacionais e organização de trabalho na escola. Editora 


\section{IMPLICAÇÕES DA GESTÃO DEMOCRÁTICA NA CONSTRUÇÃO DO}

Ática, São Paulo, 1998.

RECIFE. Conselho Municipal de Educação. Regimento do Conselho Municipal de Educação do Recife. Dispoível em http://www.portalcme.recife.pe.gov.br/content/regimento-doconselho-municipal-de-educa\%C3\%A7\%C3\%A3o-do-recife . Acesso em: 01 ago. 2020.

SAKATA, K. L.; LIMA, M. F. Apontamentos sobre o conceito de democracia em Joseph A. Schumpeter e Jürgen Habermas. In: Jornal de Políticas Educacionais. Vol. 12 Num. 15. 31 de agosto de 2018. Disponível em file:///C:/Users/joser/Downloads/59183-242831-1-PB.pdf . Acesso em 10 out. 2020.

TRIVIÑOS, Augusto Nibaldo Silva. Introdução à pesquisa em ciências sociais: a pesquisa qualitativa em educação. São Paulo: Atlas, 1987. 